\title{
Education \& Entrepreneurship: Implications For Contemporary Microfinance
}

\author{
Alan M. Gnegy, West Virginia University, USA \\ Alan J. Wilson, West Virginia University, USA \\ Albert Sementa, West Virginia University, USA \\ Aman McWilliams, West Virginia University, USA \\ Caitlin Helmer, West Virginia University, USA \\ Jacob Kidwell, West Virginia University, USA \\ Kelsey L. Swaim, West Virginia University, USA \\ Presha E. Neidermeyer, Ph.D., CPA, West Virginia University, USA
}

\begin{abstract}
In world regions receiving direct foreign aid, beneficiaries of aid often lack the education required to remove themselves from poverty. Micro-lending refers to the initiation of small loans to the neediest of borrowers who are unable to secure traditional financing from financial intermediaries. In order for micro-lending to thrive as a viable alternative to traditional government aid, borrowers must not only receive a loan, but also an education in business to fully equip borrowers with necessary resources to establish and operate a prosperous business entity. The authors will argue for the provision of increased educational resources and discuss the disparities between the US model of education and that of third-world nations. Furthermore, the authors will prescribe steps to develop educational materials and train micro-credit borrowers to better guarantee the viability of microfinance.
\end{abstract}

Keywords: Micro-Lending; Microfinance Sustainability; Poverty Relief; Microfinance Regulation; Education

\section{INTRODUCTION}

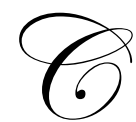

urrent news media continues to report an image of micro-lending that tarnishes Muhammed Yunus' highly esteemed method to alleviate global poverty. Recent articles illustrate the exploitation of the world's poorest for the sake of profit by those engaging in corrupt lending practices. Extending loans to impoverished citizens of society without also providing education creates the disaster story currently unfolding before the news media today. Furthermore, allowing self-regulation on behalf of lenders offers itself to a lack of consistent processes for the application, initiation, and follow-up tracking of loan proceeds delivered. In this paper, the authors will argue for the importance of education in the loan process and will comment on the potential benefits and drawbacks of regulatory oversight for microfinance initiatives.

\section{LOAN PROCESS}

In order to promote entrepreneurial pursuits within third world countries, the overall micro-lending process gives indigent citizens an opportunity to expand on their businesses without an excessive amount of financial burden. This process is very similar to that of providing a standard loan where the two parties involved are the lender and borrower. Whereas a standard loan may be secured by substantial collateral, micro-loans have historically been unsecured. As default rates increase, micro-lenders are beginning to require collateral from mandatory savings accounts before initiating a micro-loan. The amount of the mandatory savings is usually stated as a percentage of the amount borrowed, and is returned to the borrower at the end of the loan duration, in the absence of default. Although the mandatory savings is a means of security for the lender, it also serves the purpose of demonstrating to the lender that the borrower has the ability to generate sufficient cash flows. 
With regard to the principal borrowed, it is significantly less than that of the principal borrowed with a standard loan, falling within the range of $\$ 100$ to $\$ 1,500$. In terms of both the duration of the loan and the stated amount of interest, averages are around three (3) to six (6) months and 31\%, respectively (Clark, 2009). Interest is usually paid back on a weekly basis, with payments allocated proportionally over the entire duration of the loan. The first step of the micro-loan process is the evaluation and screening of borrowers to determine the need for and the ability to pay back financing. Although standard loans may consider quantitative and financial factors as more pertinent to the screening of a potential borrower, more qualitative factors are considered for micro-loans. If the borrower passes the evaluation process, he or she will be granted a loan that is based on the amount that the financial institution considers to be reasonable for the particular business proposition. If borrowers are rejected from even the smallest of loans, two or more borrowers may apply for the same loan and will become jointly liable if either were to default. As mentioned previously, interest is paid on a weekly basis. The principal and final interest payment is returned at the closure of the loan period. Borrowers that maintain good standing with lenders are given the opportunity to apply for larger loan amounts in the future.

\section{Need and Sustainability}

In order to ensure that micro-loans remain a permanent means of support for entrepreneurial endeavors, the overall micro-loan process must be maintained as a sustainable, viable system for financing. Rather than relying on the government for support, lenders must charge interest that correlates to both the operating and administrative costs of issuing loans. The first two aspects of the interest rate consist of the financing charge and the cost of default. Both of these charges vary, depending on the amount of the loan. The cost of default charge is implemented in order to make up for the percentage of loans that do go on default and become uncollectible. Both the financing charge and the default charge may be more significant for larger loans than those that are smaller and more easily repaid. The third aspect of the interest charge covers administrative expenses of issuing the loan. This value is usually static, regardless of the loan amount. For example, the fee for approving the loan issuance would cost the same for both a $\$ 200$ and a $\$ 1,000$ micro-loan. This same reasoning explains why interest rates for micro-loans seem so significant for borrowings of a few hundred dollars. Although all three interest expense charges may be considered burdensome, each is important in maintaining consistent lending practices within the micro-lending process.

\section{Micro-Loan Progression}

The micro-lending arena has recently reached the online market, appearing on websites such as Kiva.com and Microplace.com, giving third world entrepreneurs the opportunity to benefit from lenders on a global scale. Rather than strictly relying on local means of financing, third world entrepreneurs may contact local field partners that work directly with Kiva in providing lending services. Once the local field partner approves a borrower for financing, his or her personal story and information regarding the need for financing is posted to Kiva's website for review by potential lenders. This is truly beneficial to borrowers because it increases their chance for financing exponentially, as lenders from around the globe may contribute to their entrepreneurial pursuits. Anyone from around the globe that has access to a computer has the opportunity to view the loan requests from Kiva's website and may select an entrepreneur to provide funding. Loan amounts generally begin at $\$ 25$ and increase through increments of the same value. Also, in regards to sustainability, all interest charges are kept with the field partners in order to reimburse the operating costs of providing loan services. It is imperative that the interest charges are sufficient to cover the expense of issuing the loans.

\section{Current Trends}

Andhra Pradesh is an Indian state that accounts for 30-40\% of the $\$ 6.5$ billion micro-loan industry in India (Kazmin, 2010). An October 29, 2010 issue of the Wall Street Journal reports on the backlash of micro-lending in this state and uncovers the practice of influential political officials urging borrowers to withhold payment from lenders as they come to collect. When queried, the political officials cite exorbitant interest rates and poor lending practices as the driving force behind the borrowers' struggles. In some cases, borrowers have purportedly resorted to suicide as an escape from the pressures to repay loans. Increasing cases of borrower default are quickly engaging the media to report on the proposed derailment of the micro-lending movement. A surface investigation reveals a great deal of incongruity between lenders and the punishment of an industry by the actions of a few. 
Micro-lending serves as a more favorable alternative to government aid only when the microfinance initiative operates a sustainable business model. Unsustainable models require steady government funding and or the use of usurious rates to derive a profit. R Subrahmanyam, the Principal Secretary of Rural Development in Andhra Pradesh, describes the process as follows:

Irresponsible lending leading to multiple loans without due diligence, unproductive loans for consumption and consumer durables, lack of transparency in operations, usurious interest rates, coercive recovery practices, have all resulted in hyper-profits to microfinance institutions and impoverishment of the poor (Associated Press, 2011).

Subrahmanyam is correct in his description, although its application only extends to those engaging in such practices. Out of 260 Indian microfinance organizations, as of November 2010, 60 to 70 were at risk of collapse due to borrower default stemming from such practices. The projection was developed after the Indian state of Andhra Pradesh capped interest rates and ordered monthly payment collection versus the previous weekly collection practice. With the typical Andhra Pradesh household having an average of 9.6 loan accounts, a great deal of revolving credit remains outstanding from the perspective of lenders. As of November 2010, microfinance organizations were in search of nearly $\$ 221$ million in loans for liquidity to buffer the cash flow freeze (Lee \& Alexander, 2010).

When viewing the composition of the typical micro-loan recipient, education comes to the forefront. In response to micro-loan failures, a reporter in Lagos, Nigeria, comments, "staff of microfinance banks should be trained to be teachers, advisers and mentors... the guiding philosophy should be centered on helping somebody to escape the poverty trap." While any lender engaged in charging exorbitant rates and predatory lending is certainly responsible for their contribution to the micro-loan crisis, all lenders are held responsible for the education of their borrowers. An element of moral hazard enters a transaction whereby loans are made to those who do not understand general business principles (Ayodele \& Sotola, 2010).

\section{Micro-lending Sustainability}

The non-profit Unite for Sight identifies four issues regarding current micro-lending practices; high interest rates, lack of sustainability, lack of business education, and lack of social awareness. Micro-lending models must be tailored to the geographic region in which the initiative deploys (Unite for Sight, 2010). Key elements in achieving sustainability include education, regulation, and awareness. These three elements affect both the borrower and lender and combine synergistically to form a sustainable venture.

\section{EDUCATION}

A positive correlation exists between the level of education an entrepreneur possesses and his or her success in the initial stages of self-employment. There are two important forms of data that should be considered when analyzing this correlation. First, studies that conduct raw data collection and analysis prove useful to establish the unbiased existence of a statistically significant correlation between educational histories and entrepreneurial success. However, studies of this sort only go so far in explaining the relationship between an entrepreneur's level of education and his probability of becoming successful as a self-employed businessperson. The second type of evidence to be considered is firsthand testimony of entrepreneurs who have experienced the challenges associated with designing and implementing a successful business plan. This helps to explain the interplay between educational background, personality, and entrepreneurial success.

\section{The Link between Education and Entrepreneurship}

The association between "human capital" and entrepreneurial success has been the subject of many detailed studies. Generally, human capital is defined to include educational background, relevant work or professional experience, and also certain demographic characteristics such as age or gender. In many cases, some degree of positive correlation exists between educational background and entrepreneurial growth and success. Generally, entrepreneurial endeavors undertaken by proprietors with college degrees tend to exhibit higher rates of success than similar ventures by less educated entrepreneurs. In a study of 217 successful American entrepreneurs, researchers 
found that most of the respondents had attended college in spite of their parents' generally lower levels of education. Additionally, nearly $30 \%$ of the entrepreneurs who were surveyed had earned graduate degrees (Hisrich \& Brush, 1986). Another study from Purdue University in 1985 surveyed and tracked nearly 3,000 entrepreneurs over the course of approximately three years in order to analyze the relationships between various human capital "predictors" (including education) and subsequent entrepreneurial performance. Researchers concluded that "overall, performance appeared to be enhanced by level of education" (Cooper, Gimeno-Gascon, \& Woo, 1994). Educational experiences may help develop problem solving skills in students, as well as foster a sense of determination or perseverance which later become valuable assets in the entrepreneur's professional arsenal. Studies like the ones mentioned above can serve to document the existence of a statistically significant correlation between varying levels of education and entrepreneurial success in subsequent business ventures.

\section{Entrepreneurial Testimony: Understanding the Correlation}

In order to get a better picture of this correlation between education and business success, it becomes useful to examine the firsthand testimony of entrepreneurs who have experienced the difficulties of starting a new business. The aforementioned study of 217 entrepreneurs also asked respondents questions concerning the most difficult problems that they encountered when beginning their business ventures. The entrepreneurs' answers speak volumes about the importance of basic business education when creating and implementing a business plan. Of the top three most problematic issues for new entrepreneurs, numbers two and three relate directly to educational background (or lack thereof). Nearly a quarter of the study's respondents cited "Lack of Business Training," and "Lack of Management Experience" as major issues encountered during the start-up phase of their businesses (Hisrich \& Brush, 1986). The subjects of this particular study also included advice for potential entrepreneurs who believe that their educational backgrounds may be insufficient. The entrepreneurs urged small business owners to return to college, attend seminars \& conferences, read trade publications, or seek out continuing education courses to bolster their educational foundations. One respondent emphasized the importance of business education by urging new business owners to "learn business administration skills before starting a business so skills do not have to be learned on the job" (Hisrich \& Brush, 1986) By applying these firsthand perspectives to the aforementioned statistical correlation between education and entrepreneurial success, it becomes increasingly apparent that strong educational foundations in core business concepts can help give potential entrepreneurs an advantage over their less educated competitors. Having a preliminary understanding of business administration and related concepts can assist owners of start-up businesses in the prevention of trial and error processes that less educated entrepreneurs may be forced to undertake.

\section{EDUCATION AND APPLICATIONS FOR MICROFINANCE}

The previously cited studies focus on American entrepreneurs operating in the capitalist economic structure of the United States. This Western focus is due in large part to the anecdotal research of entrepreneurs using microloans to finance endeavors in African or Asian regions of the world. However it still seems reasonable to expect that educating micro-loan applicants on basic business processes \& concepts would generate some benefit for them as they undertake the initial steps in establishing their new business ventures.

\section{Lender's Role in Education}

In order to provide the best possible chance of success for those obtaining micro-loans, lenders must offer education in business-related principles for borrowers. This education entails all of the major aspects of creating a business along with the precise details of the loan.

The lender should provide the specifics of the loan to the recipient. Borrowers must have knowledge of loan terms and principles in order to understand what amount needs to be repaid and when to make the repayment. Additionally, the total amount of interest that will be accumulated over the life of the loan and the specific dates of repayment must be provided. The borrower should be made aware of whether the loan being made is secured or unsecured. Furthermore, consequences of default, including repossession, must be stressed. Repayment schedules and interest rate calculations should be explained in detail with the potential borrower to reinforce the point that the loan must be repaid at specific dates. 
Receiving a loan to start a business will have served no purpose if the recipient is unable to run a profitable business. The lender must stress that the benefit of the loan is only to be used for a business idea that will provide a sustainable income. The loan cannot be used to obtain personal goods or items that will provide no future income or cash flow. Lenders should help borrowers turn a potential idea into a successful business model. In order to accomplish this, education in the design and implementation of a business model along with daily operations management is critical.

Topics that should be addressed with regards to designing an effective plan for a business entity include an introduction to recordkeeping, budgeting and pro forma statements, and daily operations. The basics of recordkeeping provide the framework for accounting principles including the basic accounting equation. These accounting terms should be defined; however, examples of terms with which borrowers will be able to relate should also be given. Using visual aids to help teach concepts, such as revenues and expenses, will be quite beneficial in helping borrowers achieve a more complete understanding of the principles. Examples of various transactions, such as making a cash sale or buying items on credit, should be covered. Teaching transaction analysis and how to balance the basic accounting equation will help the future business owner keep track of each type of dealing that occurs in the business.

Budgeting should include the basics of forecasting projected sales in order to properly plan for future needs. Knowing the difference between variable and fixed costs is crucial for a beginning business owner. One of the most important formulas to convey is breakeven analysis as it will provide the borrower with an estimate of how many units must be sold in order to cover fixed costs. The format of the pro forma statements should also be covered. Having knowledge of financial statements will help the borrower to compare current and prior year's performance. Being able to put together the financial statements of the business will greatly benefit the business owner when lenders require documentation.

How to achieve efficiency in daily operations is perhaps the most important aspect of the instruction given to potential borrowers. The use of appropriate recordkeeping must be stressed in order to ensure that business assets are kept safe and not used for personal consumption. The concept of an audit should be explained in order for business owners to see if their records convey what they actually have. Many businesses requiring micro-loans will barter for goods as often as making purchases, thus accounting for bartered transactions is also a critical learning point.

Lenders must be certain the borrower fully understands the details of the loan and repayment plan before the loan is approved. Many defaults on loans can be avoided by creating a complete understanding and mutual agreement between the lender and borrower. The role of the lender in education must extend beyond that of the standard educational classroom. Micro-loan lenders must always keep in mind that micro-loans were created for the benefit of the borrower living in poverty. Strides must be made to help those in poverty by providing them with all of the necessary tools to achieve economic sustainability.

At first glance, it may seem like an unreasonably difficult proposition to suggest that microfinanciers should take measures to educate loan applicants on basic business concepts. After all, the microfinance institutions exist to provide financial capital, not human capital. However, there are a few important considerations to be taken into account at this point. First, depending on the costs of administering these educational services and the reductions in default rates that actually materialize as a result, it could be in the microfinancier's best interest to provide such services. Another important consideration is the likely intergenerational transfer of "invested" human capital from parents to children. Given the impoverished conditions of many world regions that are targeted for microfinance, it is logical to assume that a successful entrepreneur in such a region would naturally pass the skills of his trade on to his children. In fact, a study of approximately 500 business owners revealed that roughly half of the self-employed respondents were second-generation entrepreneurs. Additionally, researchers concluded that parentchild transfer of "human capital" seems to serve as an effective substitute for more formal business education (Lentz \& Laband, 1990). This research is especially relevant for the underlying social goals of microfinance because it seems to indicate that relatively small investments in educating potential entrepreneurs can develop into an intergenerational, self-perpetuating cycle of empowerment. This hypothesis also fits nicely into the overarching theme for the social goals of microfinance - that enabling the world's poor to provide for themselves is more 
sustainable than providing for the world's poor now and in the future. While further research is necessary to understand the implications of this supposed intergenerational transfer of human capital on the theory of microfinance, it is probable that small investments in entrepreneurial education today could generate substantial returns for both present and future generations.

\section{AWARENESS: CULTURAL IMPLICATIONS FOR ENTREPRENEURIAL EDUCATION}

If entrepreneurial education can offer microfinance any significant gains in terms of better equipping startup businesses with the requisite human capital to survive, then it is worth taking a closer look at the educational methods specifically. Entrepreneurship certainly seems like a global phenomenon, having certain commonalities across diverse cultures as citizens in a community perceive a need and a potential for personal gain by meeting that need. Teaching and learning, in contrast, seem to be processes that are highly dependent on cultural influences and regional customs. Researchers are becoming increasingly aware of the interplay between the subtleties of culture, and the variability of effective teaching methods in those cultures. One study published in Management International Review examined the learning styles of mid-level managers from several world regions including Eastern Africa, India, and the United Kingdom. The researchers reinforced the notion of culturally dependent learning styles, and concluded that there are "important cultural differences in the learning styles of managers" (Hayes \& Allinson, 1988). The following analysis will focus on two major world regions in which the theory of microfinance has been applied: Asia and Africa. It is important to remember that culture's influence on behavior is highly variable and contingent on countless personal factors that will differ among individuals. Therefore, the cultural phenomena discussed in subsequent paragraphs must not be over generalized to an entire continent or country. Planning and implementing a microfinance institution, like any other business plan, requires extensive forethought and research. Any endeavors to apply the educational proposal presented in this paper should be accompanied by regionally specific research in order to understand the particular cultural tendencies with which educators will be dealing. Lender awareness is a key to sustainable micro-lending and is developed through the process of breaking down larger norms into local variations.

\section{Asia}

Traditional Asian cultures offer a stark contrast from the individualistic tendencies found in most major Western societies today. Hofstede (1980) studied an organization worldwide to determine elements of culture. He found four cultural variables. Of these variables, the one most often isolated for analysis with respect to Asian cultures is Individualism vs. Collectivism. Essentially, this cultural variable measures how much a culture tends to emphasize individuals with respect to the group. While the United States and Western Europe tend to place comparably more emphasis on individuals, Asian cultures often de-emphasize the individual in order to give more consideration to the collective. This basic cultural contrast can have major implications for teaching and learning in many Asian cultures.

A study from Griffith University in Queensland, Australia, examined the cultural influence on learning styles of accounting students from Taiwan, Hong Kong, and Australia. More specifically, researchers considered the effect that the individualism/collectivism dynamic would have on the learning styles of students from Asian cultures as compared with the students from Australia's more Westernized culture. Overall, the study demonstrated that Asian students tended to have more passive, reflective, and abstract learning styles than their Australian counterparts. For example, Asian students exhibited a stronger tendency to observe and reflect on the instructor's message rather than become actively involved in the teacher-student dynamic occurring in the classroom. This tendency likely stems from the Asian emphasis on the learning process as an external transfer of knowledge from the expert/teacher to the student. Students tend to view the teaching-learning interaction as a collective process, and are urged to carefully observe and reflect instead of interjecting personal or unique interpretations. In contrast, contemporary Western learning environments often de-emphasize the role of the instructor which tends to promote more individual participation in the learning environment. Researchers suggested that another important distinction between the two cultural learning styles is that Western students tend to view the learning process as an individual process in the sense that every student is personally responsible for his or her own learning. Asian students, on the other hand, exhibited a greater tendency to view the learning process as an external knowledge transfer which occurs in the collective learning group. This differing perception about whether the individual or the collective is the focal 
point of the learning process also influences how the role of the instructor is defined for students from Asian and Western cultural backgrounds. Students from Western cultures often view an instructor as a guide or companion meant to assist students in their own personal educational pursuits. Note that this view of an instructor is consistent with the overarching tendency to classify learning as an individual process. In contrast, Asian students tend to view the instructor as playing a more central, authoritative role in the learning environment, and this characterization is exhibited in the more unilateral transfer of information from teacher to student. Again, this perception seems consistent with the overarching theme of Asian students viewing the learning process as a collective initiative with less emphasis on the individual (Auyeung \& Sands, 1996). These cultural subtleties about how education is perceived in Asian \& Western cultures directly govern the interpersonal interactions that take place between teachers and students in a classroom environment.

In addition to understanding the interpersonal dynamic of Asian learning environments, it is also important to examine the psychological learning methods employed by many Asian students when learning new information. The Griffith University study found that Asian students tend to be more concerned with discerning and understanding what is true when processing new information rather than focusing primarily on those aspects of the information that are immediately practical and applicable. Additionally, the Asian students from the study exhibited a stronger tendency to use logic to build abstract concepts, while their Western counterparts often placed more emphasis on concrete examples or applications of the information being presented. These psychological tendencies are labeled as "Reflective Observation," and "Abstract Conceptualization" (Auyeung \& Sands, 1996). Overall, the Asian accounting students tend to process new information on a more abstract level than their Western counterparts, and this tendency is accompanied by a related de-emphasis of concrete and practical applications or examples.

\section{Africa}

In general, the interplay between traditional African cultures and predominate learning styles therein is not as well understood as the relationship between Asian culture and learning styles. Nonetheless, cultural tendencies in many African communities can have a very powerful influence over both the interpersonal interactions between teachers and students and the manner in which African students process new information on a psychological level.

There are a few cultural commonalities in many African communities which govern the interactions between students and teachers in a learning environment. African culture tends to place a greater emphasis on the views and opinions of the designated leader than do many Western cultures. This cultural concept may lead group members to choose to defer personal views or interpretations in favor of expressing consensus with the group's leader. This phenomenon has several important implications for the classroom environment. Since the instructor is naturally occupying the role of a leader, it can become difficult to engage students in discussion because expression of individual views or interpretations is not encouraged and is often discouraged in many African cultures. Researchers with firsthand experience in teaching African students assert that many African cultures intentionally foster a dependent relationship between teachers and students as a demonstration of a student's respect for the teacher's wisdom and expertise. The result of this interpretation of the learning process is that many educational environments exhibit passive teacher-student interactions with very few questions being asked, and even fewer dissenting viewpoints being offered. This difficulty in facilitating student questions is further exacerbated by a common cultural interpretation of direct questions. Many African cultures view a direct question as an insult, and tend to "soften" the inquiry with an accompanying proposal for an answer (Sawadogo, 1995). The classroom environment which results from these cultural tendencies is often characterized as very learner-passive with mostly unilateral informational transfer. As is the case in Asian cultures, this learner passivity is often misinterpreted as a lack of interest or motivation when in fact the students are only operating within the bounds of their typical cultural expectations.. The aforementioned tendency to defer one's own views to the opinions of the group's leader should be carefully considered when planning any group activities or exercises where students will be operating as small subunits within the greater classroom environment. If the subdivided student groups do not contain students of roughly equal perceived "status," the tendency for them to defer to authority. When student groups are not carefully selected with demographically homogenous individuals, the group's members may choose to prioritize the group leader's viewpoints over any personal interpretations. One African educator summarizes the social interplay like this, "Competition ensues to see who can best rephrase and agree with the leader's viewpoint..." (Sawadogo, 1995). 
Understanding the interpersonal relationships in a traditional African learning environment will not completely equip an educator to effectively transfer knowledge in such a setting. Attention must also be paid to the manner in which many African students tend to psychologically process new information. Much like the Asian cultures examined previously, many African students exhibit more reflective tendencies than do Western students. African learning processes usually involve careful, passive observation and subsequent reflection on the material as opposed to active individual participation in lessons. Another interesting phenomenon in many African cultures is the general appreciation for lecture. As contemporary Western educators join the movement toward "active learning" and focusing on student involvement in the learning process, lessons with the traditional lecture format are naturally being de-emphasized in the United States. However, many African cultures place great value on oral lectures and the accompanying memorization processes performed by the students. One researcher speculates that this cultural affinity for lecture and memorization stems from a very long and rich history of oral tradition in many African cultures (Sawadogo, 1995). The final, and perhaps most important note on this topic relates to message structure. Many Western educators and students prefer information in a lesson to be presented in a sort of categorical or analytical structure. In contrast, African students exhibit a greater preference for highly repetitive, narrative formats when receiving new information (Sawadogo, 1995). It is possible that this preference also stems from rich oral history where narrative formats make information easier to remember and pass along.

\section{REGULATION}

It is important to understand the sociopolitical and economic factors affecting the environment in which entrepreneurs and others who wish to do business via microfinance. How institutions purvey their policy will necessarily have an inextricable effect on the nature of the business climate. As the institutional framework pertains to regulation, economist William Baumol postulates that individuals will engage in productive, unproductive, or destructive entrepreneurship depending on their incentive. If the business climate makes it more profitable for individuals to engage in productive entrepreneurship - that of mutually beneficial, voluntary exchange - the actions of individuals will have a positive effect on society. If, on the other hand, the business climate makes it more profitable for individuals to engage in unproductive or destructive entrepreneurship - that of political rent seeking, corruption, or the pursuit of lawsuits - individuals will engage in activities that leave society in either a zero-sum or negative-sum situation (Baumol, 1990).

Indeed, a comparative analysis between countries' business freedom - "the overall freedom to create and run a private enterprise" - shows that those countries that are relatively free also have relatively higher GDP's (The Heritage Foundation, 2011). According to the Heritage Foundation's Economic Freedom of the world report, relatively wealthy nations - United States, Canada, and Hong Kong - rank 91\%, 96.4\%, and 98.7\% free, respectively on business freedom. Juxtapose to various countries in Africa who are relatively poor - Democratic Republic of Congo, Eritrea, and Zimbabwe - ranking 37.8\%, 18.2\%, and 32.1\% free, respectively, an apparent correlation exist between a country's wealth, and the relative burden of operating a business.

Of course, it is particularly important to understand and keep in mind the kind of regulatory and policy environment one is dealing with when trying to facilitate microfinance. Negligence to efficiently deal with such governmental restrictions can lead to unnecessarily stifled productive entrepreneurships, thus shifting the incentives of people to unproductive and destructive forms of entrepreneurship. Expanding the argument for formalized economic policy, it becomes apparent that government holds responsibility for the establishment and enforcement of regulations over the micro-lending industry. Increasing the punishment for predatory lending practices reduces the incentive to engage in the activity and provides an integral element in the sustainability of micro-lending. There are several approaches to the regulation of micro-lenders, and this is an area for future research.

\section{CONCLUSION}

Micro-lending represents a model of social business by which relief from poverty can be achieved. Despite the recent media reports, the concept of micro-lending still offers an important alternative to traditional forms of government aid. In order to bridge the gap between theory and reality, microfinance must incorporate three broad elements : education, awareness, and regulation. Lending to uneducated borrowers and failing to adequately prepare them for business contributes to the lender's moral hazard. Employing a highly mechanized operational structure 
across many regions of diversity disregards the fundamental purpose of micro-lending. Lending in an unregulated environment presents the incentive to sacrifice social gains for short-sighted profits. Micro-lending is about more than reducing government expenditures on poverty relief. The objective is to improve overall quality of life, which involves education, economics, and environment. Through direct or indirect regulation, awareness of cultural differences, and an emphasis on teaching before lending, microfinance prospers.

\section{AUTHOR INFORMATION}

Alan Gnegy is a senior accounting major at West Virginia University. He was born and raised in Oakland, MD, and plans to pursue his CPA license while working at a public accounting firm after his graduation in May 2012. Alan has work experience as a Managerial Accounting Intern for Pillar Innovations, LLC of Grantsville, MD and as an Audit/Advisory Intern for KPMG, LLP in Pittsburgh, PA. During his time at WVU, Alan has involved himself in various student organizations on campus and participated for two years as a Big Brothers/Big Sisters volunteer in the Morgantown area.

Alan J. Wilson holds a Bachelors Degree in Business Administration with a major in Accounting from West Virginia University and is currently pursuing a law degree at West Virginia University. Alan interned at a multistate holding company prior to interning at KPMG where he worked in both the financial services audit practice and the state and local tax practice. Alan's research interests include banking, microlending and personal financial planning.

Albert Sementa graduated with a Bachelors of Science Degree from West Virginia University with a major in accounting. He worked as a writing tutor for the WVU writing center and was an active member of Alpha Kappa Psi. Albert will continue his education at Michigan State University College of Law in the fall of 2011. Upon graduating from law school, he plans on utilizing both his accounting and law degree by pursuing a career as a tax attorney

Aman John McWilliams is a paid video blogger on YouTube better known as "AmanJohnK" with a secondary channel titled "AmanJohnX". A member of Phi Beta Kappa and student government, Aman graduated summa cum laude in Economics, with a minor in Psychology, from West Virginia University. His online content focuses on personal success and fulfillment, and is known for his humorous, entertaining, yet passionate and inspiring delivery. While Aman's primary channel draws inspiration largely from psychology, the neurosciences, and personal experience, Aman's secondary channel centers heavily around ethics and political philosophy. Aman currently has over 14,000 subscribers worldwide

Caitlin Helmer is a graduate of the West Virginia University College of Business and Economics and is a West Virginia Honors Scholar.

Jacob Kidwell graduated in 2011 Summa Cum Laude from West Virginia University with a Bachelor of Science Degree in Accounting. He completed the Graduate Certificate in Forensic Accounting and Fraud Investigation from WVU in July 2011 and is currently pursuing a Master of Professional Accountancy Program at West Virginia University and am working as a graduate assistant for the WVU Office of the Provost.

Kelsey Swain earned her Bachelor's of Science in Business Administration with a Major in Accounting from West Virginia University, and is currently attending The Penn State Dickinson School of Law.

Presha E. Neidermeyer, Ph.D., CPA is a Professor of Accounting in the West Virginia University College of Business. She works with the WVU Honors College to coordinate the B\&E Honors Capstone for WVU Honors Scholars. She is a board member for E4P (http://www.e4poverty.org) a not for profit benefitting charities in the US and in Africa. Her research interests include ethics, gender studies and international accounting. E-mail: pneidermeyer@gmail.com 


\section{REFERENCES}

1. ACCION. (2011). Why and How Microfinance Works. Retrieved April 10, 2011, from ACCION: http://www.accion.com/Page.aspx?pid=1845

2. Associated Press. (2011, March 8). Microfinance Struggles to Restore its Reputation. Retrieved 12011 , April, from Microfinance Africa: http://microfinanceafrica.net/tag/microcredit-summit-campaign/

3. Auyeung, P., \& Sands, J. (1996). A Cross Cultural Study of the Learning Style of Accounting Students. Accounting and Finance, 261-274.

4. Ayodele, T., \& Sotola, O. (2010, July 6). Nigeria: Rethinking Microfinance Strategies. Retrieved April 1, 2011, from allAfrica.com: http://allafrica.com/stories/201007070376.html

5. Baumol, W. (1990). Entrepreneurship: Productive, Unproductive, and Destructive. Journal of Political Economy, 893-921.

6. Clark, J. (2009, August 18). How Microlending Works. Retrieved April 14, 2011, from howstuffworks: A Discovery Company: http://money.howstuffworks.com/microlending2.htm

7. Cooper, A., Gimeno-Gascon, F., \& Woo, C. (1994). Initial Human and Financial Capital as Predictors of New Venture Performance. Journal of Business Venturing , 371-395.

8. Drayton, B., \& Budinich, V. (2010). A New Alliance for Global Change. Harvard Business Review , 56-64.

9. Hayes, J., \& Allinson, C. (1988). Cultural Differences in the Learning Sytles of Managers. Management International Review , 75-80.

10. Hisrich, R. D., \& Brush, C. (1986, October). Characteristics of the Minority Entrepreneur. Journal of Small Business Management, 1-8.

11. Hofstede, G. Culture's Consequenses. Sage Publications: London, UK.

12. Kazmin, A. (2010, October 14). Andhra Pradesh to curb India microfinance. Retrieved April 15, 2011, from Financial Times: http://www.ft.com/cms/s/0/304915e8-d7b1-11df-b478-00144feabdc0.html

13. Lee, Y., \& Alexander, G. S. (2010, November 22). India's Microfinance Clampdown May Trigger Failures, World Bank Aide Says. Retrieved March 12, 2011, from Bloomberg: http://www.bloomberg.com/news/2010-11-21/india-s-smaller-micro-lenders-likely-to-fail-srinivasan$\underline{\text { says.html }}$

14. Lentz, B., \& Laband, D. (1990). Entrepreneurial Success and Occupational Inheritance among Proprietors. The Canadian Journal of Economics, 563-579.

15. Sawadogo, G. (1995). Training for the African Mind. International Journal of Intercultural Relations, 281-293.

16. The Heritage Foundation. (2011). Ranking the Countries. Retrieved April 19, 2011, from 2011 Index of Economic Freedom: http://www.heritage.org/index/ranking

17. Unite for Sight. (2010). Pitfalls in Microfinance. Retrieved March 26, 2011, from Unite for Sight: http://www.uniteforsight.org/pitfalls-in-development/pitfalls-in-microfinance\#_ftn9 